\title{
Medição e gestão de desempenho em empresas construtoras
}

\author{
Performance measurement and management in building \\ companies
}

\begin{abstract}
Luis Felipe Cândido
Sergio Henrique de Oliveira Lima J ose de Paula Barros Neto

\section{Resumo}

A

literatura sobre medição e gestão de desempenho mostra o estágio ainda embrionário desses processos na indústria da construção. Assim, este trabalho tem como objetivo avaliar os processos de medição e gestão de desempenho no setor de construção. Por meio de três estudos de caso em empresas construtoras evidencia-se que os sistemas de medição de desempenho (SMD) em uso nas empresas estão focados apenas em aspectos operacionais da medição de desempenho, não sendo, portanto, capazes de promover uma gestão que integre finalidades mais estratégicas, como influenciar o comportamento dos atores e proporcionar aprendizado e melhoria, elementos fundamentais para o alcance dos objetivos organizacionais. Assim, o estudo contribui com a literatura de gestão da construção ao aprofundar e ampliar as discussões sobre os conceitos de medir e gerar o desempenho, trazendo as novas formas de examinar o tema com base em diversos conceitos que ascendem principalmente das ciências administrativas e econômicas. Contribui também ao expandir a evidência empírica que reforça a evolução lenta dos SMD no setor de construção.
\end{abstract}

Palavras-chave: Medição de desempenho. Gestão de desempenho. Sistema de indicadores. Gestão estratégica.

${ }^{1}$ Luis Felipe Cândido ${ }^{1}$ Universidade Federal do Ceará Crateús - CE - Brasil

\footnotetext{
${ }^{2}$ Sergio Henrique de Oliveira

2Universidade Federat do Universidade Federal do Cariri J uazeiro do Norte - CE - Brasil
}

${ }^{3}$ J ose de Paula Barros Neto 3 Universidade Federal do Ceará Fortaleza - CE - Brasil

Recebido em 27/01/19 Aceito em 04/05/19

\section{Abstract}

The literature on performance measurement and management shows the embryonic stage of these processes in the construction industry. Thus, this paper aimed to evaluate the Performance Measurement and Management (PMM) process in the construction sector. A multiple case study in three construction companies showed that the performance measurement systems (PMS) in use in these companies are focused on operational aspects of performance measurement, and are unable to promote their integrated management for more strategic purposes, such as influencing the behaviour of the actors and providing learning and improvement, fundamental elements to the successful of any organisation. Thus, this study contributes to construction management literature by expanding and deepening the discussion on the differences between measuring and managing performance, offering new ways to interpret the PMM, based on different concepts emerging from administrative and economic disciplines. This project also contributes by offering empirical evidence that reinforces the slow evolution of this subject in the construction sector.

Keywords: Performance measurement. Performance management. Performance indicator system. Strategic management. 


\section{Introdução}

Medir o desempenho organizacional tem sido um dos requisitos mais desafiadores para as organizações (EVANS, 2004) e ainda é fruto de amplo debate (BITITCI et al., 2018). Desde que os sistemas de medição de desempenho evoluíram de uma simples ferramenta de controle (SINK; TUTTLE, 1993), focada em medidas de desempenho financeiro e de produtividade (GHALAYINI; NOBLE, 1996), para um processo de gestão cíclico e mais abrangente (THE EUROPEAN..., 2014), a literatura aponta que compreensão desses sistemas ainda está incompleta (HULL, 2018).

Nesse sentido, modelos tradicionais baseados em contabilidade financeira têm sido cada vez menos empregados, e aspectos mais qualitativos - como satisfação dos clientes, processos internos, aprendizagem e crescimento - têm sido incorporados à medição de desempenho (KAPLAN; NORTON, 1992). O enfoque dos modelos também mudou. Outrora concentrada em desafios intraorganizacionais, a medição tem se direcionado cada vez mais aos desafios interorganizacionais, avaliando toda a cadeia de valor (FOLAN; BROWNE, 2005), devido à necessidade de incorporar a contribuição dos diversos stakeholders envolvidos no processo do negócio (NEELY; ADAMS; CROWE, 2001).

De fato, os modelos têm evoluído na busca da gestão de desempenho integrada (BITITCI et al., 2012), avançando para além do controle técnico e incorporando princípios de controle social. De acordo com Smith e Bititci (2017), o controle técnico se refere ao processo racional, planejado, burocrático e estrutural da organização. Ainda para os autores, o conceito de controle social se relaciona com aspectos emergentes, culturais e comportamentais, que, na opinião de Bititci et al. (2018), definem como o sistema de medição de desempenho pode ser utilizado para gerenciar o desempenho da organização.

Nesse ponto específico, aponta-se preliminarmente a gestão do desempenho como processo que ajuda as organizações a estabelecer metas e a acompanhar o progresso ao longo do tempo (OKWIR et al., 2018), diferenciando-se da medição de desempenho, esta compreendida como "[...] o processo de quantificar a eficiência e a efetividade de uma ação [...]” (NEELY; GREGORY; PLATTS, 1995, p. 80, tradução nossa), ou seja, a medição de desempenho está intrinsecamente ligada à geração de informação do desempenho, e a gestão está relacionada às ações para melhorá-lo.

No entanto, tais avanços não se deram de forma similar nos diversos segmentos econômicos. Na construção civil - campo de investigação do presente estudo - a evolução das práticas de medição de desempenho se deu de forma mais lenta quando comparada a outras indústrias (DENG; SMYTH; ANVUUR, 2012). Tal afirmação denota a necessidade de estudos para a melhoria dos sistemas de medição utilizados pelas empresas do setor (KORDE; LI; RUSSELL, 2005; NUDURUPATI; ARSHAD; TURNER, 2007; DENG; SMYTH; ANVUUR, 2012), cujas principais iniciativas se deram por meio de clubes de benchmarking (COSTA et al., 2006).

Todavia, a implementação de indicadores de desempenho nas empresas de construção fortemente incentivadas pela participação em clubes de benchmarking parece não ter sido suficiente para consolidar esse processo, tanto do ponto de vista teórico (CÂNDIDO; LIMA; BARROS NETO, 2016) quanto no que diz respeito às práticas consolidadas nas empresas (SOUSA; CÂNDIDO; BARROS NETO, 2018).

Ademais, mesmo com a numerosa literatura sobre o tema, ainda se observa a necessidade de desenvolver sistemas de medição de mais fácil aplicação (KUENG; ANDREAS; WETTSTEIN, 2001; YANG et al., 2010) ou de criar condições internas para que as empresas usem adequadamente os sistemas de que já dispõem (TATICCHI; TONELLI; CAGNAZZO, 2010). Isso se torna ainda mais crítico no setor da construção, em que ainda se verifica sua ineficiente utilização (MAYA, 2016; VILLARREAL; PELLICER; RODRIGUEZ, 2017).

Assim, esforços continuam sendo envidados, tanto por pesquisadores de gestão na construção (AFTAB et al., 2016; HU; LIU, 2016; MAYA, 2016; VILLARREAL; PELLICER; RODRIGUEZ, 2017) como nas ciências administrativas (BITITCI et al., 2012; O'CONNEL; O'SULLIVAN, 2014; BOURNE et al., 2018; LAMPREIA; MAJOR, 2017; FRANCO-SANTOS; OTLEY, 2018; HULL, 2018), visando consolidar a medição e a gestão do desempenho nas organizações.

Dessa forma, esta pesquisa teve por objetivo avaliar os processos de medição e gestão de desempenho no setor de construção. Para tanto, realizou-se um estudo de múltiplos casos com base em um protocolo estruturado de avaliação de desempenho previamente identificado na literatura (CÂNDIDO; LIMA; BARROS NETO, 2016), ao qual foram incorporados critérios de investigação qualitativa com o intuito de identificar como as empresas construtoras têm medido e gerenciado o desempenho. Destacou-se, por fim, a incipiência de estudos da literatura de gestão da construção que evidenciam a distinção entre medir e gerir o desempenho, a destacar os estudos de Cândido, Lima e Barros Neto (2016) e de Sousa, Cândido e Barros Neto (2018). 


\section{Referencial teórico}

\section{Medição de desempenho e gestão do desempenho}

Diversos modelos para concepção e implantação de um sistema de medição de desempenho são encontrados na literatura. Entre eles, segundo Kennerley e Neely (2002) e Neely et al. (2000), destacam-se:

(a) Matriz de Desempenho;

(b) Modelo de Fitzgerald et al. (1991);

(c) Pirâmide de Desempenho ou Pirâmide SMART (Strategic Measurement and Reporting Technique);

(d) Balanced Scorecard; (v) Modelo de Brown (1996);

(e) modelos baseados em qualidade (EFQM Excellence Model); e

(f) Prisma de Desempenho.

Pode-se destacar ainda a Análise de Sistemas Gerenciais, proposta por Sink e Tuttle (1993).

Esses modelos foram concebidos em vários setores econômicos e incorporaram principalmente os conhecimentos do campo das ciências administrativas, tais como contabilidade, recursos humanos, produção e gestão de operações, marketing, comportamento organizacional e gestão estratégica (NEELY, 1999; FRANCO-SANTOS; LUCIANETTI; BOURNE, 2012).

Por tal natureza interdisciplinar e multifacetada, não há uma definição ou estruturação universal sobre o que é a medição de desempenho (CHOONG, 2013a). Existe, assim, uma dificuldade de entendimento sobre o próprio significado de desempenho (MICHELI; MARI, 2013), de seus atributos (CHOONG, 2013b) e da estruturação, per se, de um sistema de medição (OKWIR et al., 2018; TONI; TONCHIA, 2001). Essa incompreensão semântica dificulta uma definição comum e a própria utilização dos sistemas de medição de desempenho (SMD).

O processo de medição de desempenho, portanto, é mal definido (KUENG; ANDREAS; WETTSTEIN, 2001), e sua correta concepção e implantação se tornou ainda mais complexa devido às tendências emergentes do cenário global, que envolve fatores como a colaboração multicultural, a inovação aberta, aspectos de sustentabilidade e aumento do valor do trabalho intelectual (BITITCI et al., 2012).

Assim, é possível verificar diversos recortes temáticos dentro do campo da medição de desempenho, como a influência da medição no comportamento dos colaboradores, capacidades organizacionais, alinhamento estratégico e desempenho da empresa, em termos de gestão, mercado e finanças (FRANCO-SANTOS; LUCIANETTI; BOURNE, 2012), e até mesmo as consequências negativas não intencionais (FRANCOSANTOS; OTLEY, 2018) que podem emergir por causa do uso inadequado de um SMD, como uma gestão reativa e a desmotivação (LAMPREIA; MAJOR, 2017).

Verificam-se também estudos que buscam formatar a medição de desempenho como um sistema (CHOONG, 2013a), centrando-se em sua efetivação como um processo organizacional (KUENG; ANDREAS; WETTSTEIN, 2001), o que é ainda um desafio a ser superado, conforme observaram Bititci et al. (2012), que sintetizaram a evolução reproduzida na Figura 1.

Não sendo objetivo deste trabalho analisar em detalhes cada uma das fases dessa evolução (para tanto, os autores recomendam ver Ghalayini e Noble (1996) e Bititci et al. (2012)), discute-se em maior profundidade a literatura classificada por Bititci et al. (2012) como parte das etapas de medição de desempenho integrada e gestão de desempenho integrada.

Um dos primeiros estudos a abordar a temática foi realizado por Lebas (1995), para quem a gestão do desempenho cria o contexto para alcançar o sucesso organizacional, e os indicadores de desempenho seriam o ponto de partida para que isso seja possível. Nesse ponto, o desempenho é visto como um estado futuro, ou seja, “[...] o potencial para a implementação bem-sucedida de ações, na busca de alcançar os objetivos e metas [...]” (LEBAS, 1995, p. 23, tradução nossa). Os autores concluem ainda que medir e gerenciar o desempenho são indissociáveis para que seja possível dar autonomia aos indivíduos dentro de sua esfera de controle, mostrar as relações de causa e efeito, capacitar e envolver os indivíduos, criar uma base para discussão e, assim, sustentar a melhoria contínua e apoiar a tomada de decisão. 
Figura 1 - Evolução da literatura de medição de desempenho

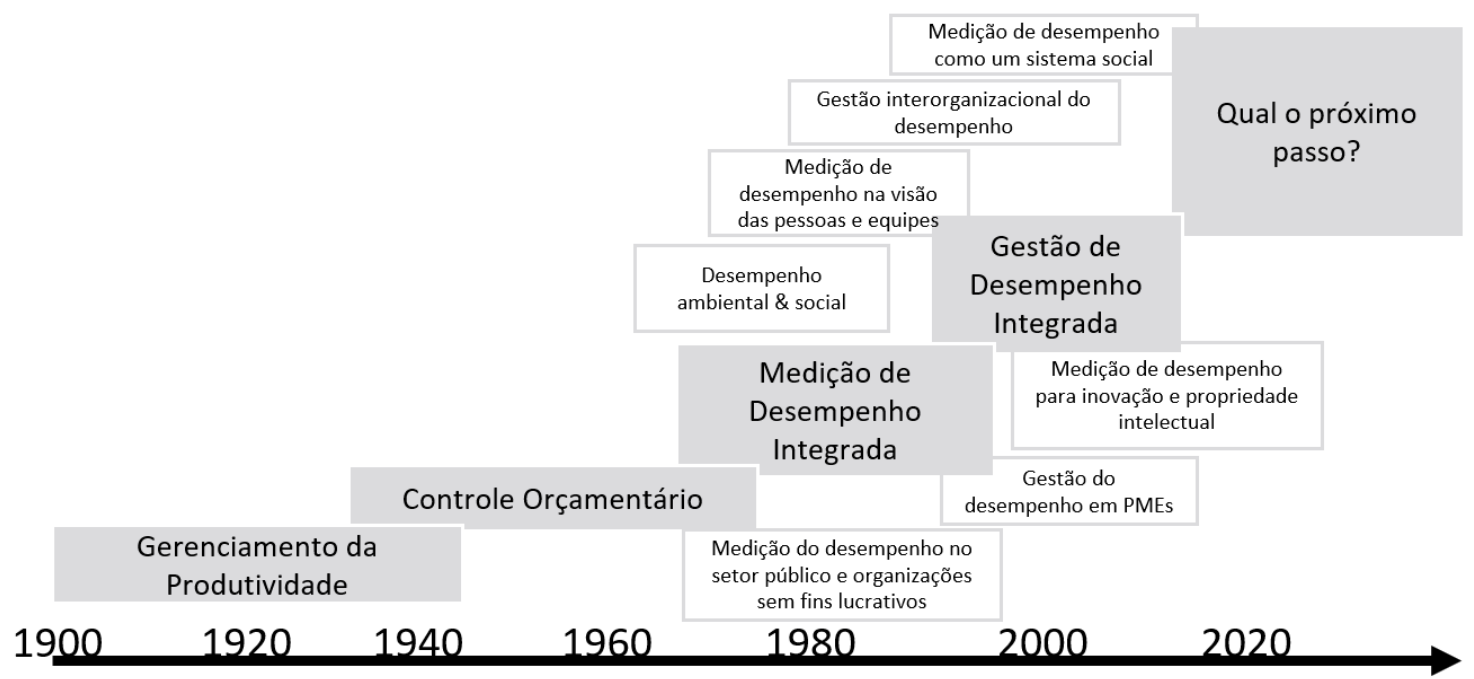

Fonte: adaptada de Bititci et al. (2012, p. 8).

Bititci, Carrie e Mcdevitt (1997) e Otley (1999) também evocam o conceito de gestão de desempenho colocando a medição como seu principal pilar, ou seja, a fonte de informações que sustenta a gestão do desempenho. Assim, a gestão de desempenho pressupõe tomada de decisão e ação com base nas informações derivadas do processo de medição de desempenho.

Isso tem levado as pesquisas na área a buscar novas formas de examinar os SMD com base em diversas teorias, que ascendem principalmente das ciências administrativas e econômicas, como a teoria do sistema dos sistemas (BOURNE et al., 2018), a teoria da agência, a teoria do caos, a teoria contingencial, a teoria dos jogos, a teoria do estabelecimento de metas, a teoria da equidade (BITITCI et al., 2018) e a teoria da complexidade (OKWIR et al., 2018).

Avança-se, portanto, de uma abordagem puramente de controle técnico, na percepção de Bititci et al. (2018), para uma perspectiva que incorpora o controle social e que considera aspectos culturais e comportamentais como base para a gestão do desempenho. Nessa nova perspectiva tem-se a gestão do desempenho como um sistema social (BITITCI et al., 2012).

Assim, autores têm diferenciado cada vez mais a medição da gestão de desempenho. Lebas (1995) aponta como preocupações inerentes à gestão de desempenho processos como treinamento, trabalho em equipe, visão compartilhada e incentivos e premiações. Lebas (1995) sugere que todas as ações que visam promover o desempenho como estado futuro dizem respeito à gestão de desempenho.

Melnyk et al. (2014) apontam a gestão de desempenho como o processo para desenvolver o conjunto de métricas, estabelecer metas, coletar, analisar, relatar, interpretar e avaliar os diferenciais de desempenho. Já Safari (2016) propõe um modelo de gestão de desempenho composto de:

(a) medir o desempenho e comunicar os resultados;

(b) recompensar e reconhecer;

(c) promover a melhoria (otimização das capacidades); e

(d) revisar os papéis da organização e das equipes.

Por fim, Okwir et al. (2018) sugerem a gestão do desempenho como um processo que ajuda as organizações a estabelecer metas e a acompanhar o progresso ao longo do tempo.

Entre os principais estudos na temática de medição de desempenho, pode-se destacar o de Franco-Santos et al. (2007). Os autores não propuseram um novo modelo, mas sistematizaram as características, papéis e processos considerados essenciais a um SMD, a saber:

(a) características:

- possuir indicadores de desempenho; e

- ter uma infraestrutura de suporte estabelecida. 
(b) papéis:

- medir o desempenho;

- gerir a estratégia;

- comunicar os resultados;

- influenciar o comportamento; e

- proporcionar aprendizado e melhoria.

(c) processos:

- definir e selecionar indicadores;

- coletar e processar os dados;

- gerenciar a informação;

- avaliar e premiar; e

- revisar o sistema.

A partir dessa elaboração, Cândido, Lima e Barros Neto (2016) argumentam que as visões de Lebas (1995) e Franco-Santos et al. (2007) são complementares e destacam os processos que podem ser considerados como medir (selecionar, definir, coletar e processar os indicadores de desempenho) e gerir - ou gerenciar - o desempenho (gerenciar as informações, avaliar e premiar, e revisar o sistema), conforme a Figura 2.

Salienta-se que cinco especialistas validaram a elaboração de Cândido, Lima e Barros Neto (2016), o que reforça a proposição teórica, cuja evidenciação empírica é pretendida na atual pesquisa. Assim, o estudo de caso realizado neste trabalho adota essa estrutura conceitual e investiga que características, papéis e processos da medição e gestão de desempenho têm sido executadas pelas empresas construtoras, expandindo a discussão em uma perspectiva mais aprofundada, conforme detalhado no método de pesquisa.

Considerou-se, portanto, que as empresas que desempenham apenas os processos de selecionar, definir, coletar e processar os indicadores de desempenho possuem sistemas de medição de desempenho. Já as empresas que avançam para os processos de gerenciar as informações, avaliar e premiar, e revisar o sistema estão exercendo a gestão de desempenho. Essa consideração se coaduna com a proposição de Smith e Bititci (2017), para quem a medição de desempenho é o componente de controle técnico, enquanto a gestão de desempenho é o componente de controle social. As duas, ao interagirem adequadamente, são capazes de elevar o engajamento e o desempenho da empresa.

\section{Evolução da medição de desempenho na gestão da construção}

A lenta evolução dos processos de medição de desempenho na indústria da construção (CÂNDIDO; LIMA; BARROS NETO, 2016) tem ocorrido basicamente por meio da incorporação de conceitos e práticas de outros setores econômicos, restando, destarte, a frequente necessidade de revisões ou adaptações conceituais (AHMAD et al., 2016).

Esforços recentes (HU; LIU, 2016; MAYA, 2016; VILLARREAL; PELLICER; RODRIGUEZ, 2017; SOUSA; CÂNDIDO; BARROS NETO, 2018) sugerem que as empresas do setor da construção ainda estão na fase de integração dos sistemas de medição, o que corresponderia ao que se evoluiu na indústria manufatureira entre os anos de 1980 e 2000 (BITITCI et al., 2012).

Figura 2 - Componentes e inter-relação entre medição e gestão do desempenho

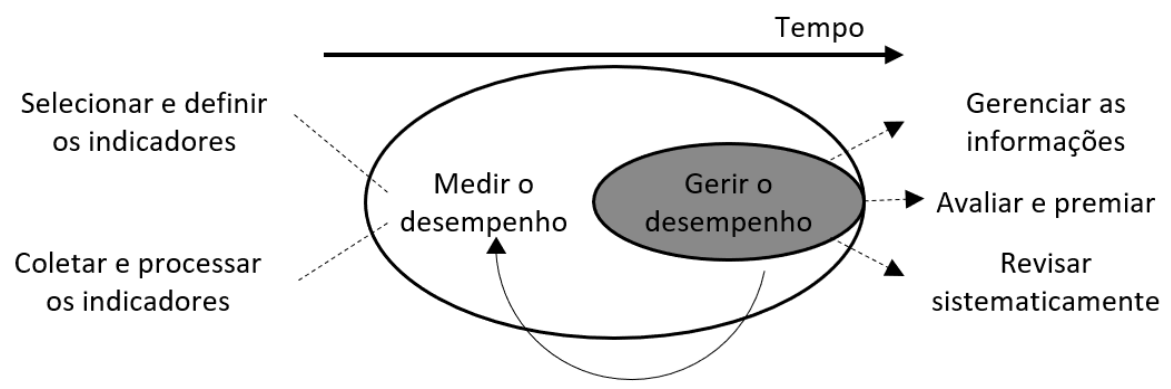

Fonte: Cândido, Lima e Barros Neto (2016). 
Essa evolução da medição de desempenho tem como características o desenvolvimento de uma abordagem mais integrada e equilibrada, bem representada pelas iniciativas de Kaplan e Norton (1992), e com maior ênfase em como os indicadores poderiam proporcionar alinhamento estratégico (BITITCI et al., 2012). Essa associação é corroborada por Ahmad et al. (2016), para os quais a indústria da construção não possui metas claras e direcionadas para manter o projeto alinhado com os objetivos estratégicos da empresa.

Nesse sentido, modelos de medição foram desenvolvidos com base no Balanced Scorecard (KAPLAN; NORTON, 1992) e em modelos de excelência em gestão, como o da Fundação Europeia para Qualidade The EFQM Excellence Model (CHENG; WEN; JIANG, 2014) e o do Malcolm Baldrige National Quality Award (MBNQA) (NEYESTANI; JUANZON, 2016).

Porém, ainda se verifica a subutilização desses modelos em empresas construtoras (MAYA, 2016; VILLARREAL; PELLICER; RODRIGUEZ, 2017), em que a medição ainda está focada nos resultados dos empreendimentos - em nível de projeto - e em seus indicadores financeiros (TSOLAS, 2011; HU; LIU, 2016).

Dessa forma, a avaliação realizada neste estudo pode ajudar a compreender a dinâmica dos SMD no setor de construção e direcionar os esforços de melhoria para a gestão integrada do desempenho (BITITCI et al., 2012), expandindo o enfoque estático e linear atual para uma abordagem multidisciplinar e multidimensional que vai além de selecionar e coletar os indicadores, passando a gerenciar a informação e avaliar e premiar o desempenho alcançado, possibilitando a aprendizagem no próprio sistema e habilitando a capacidade de revisá-lo.

\section{Método}

Esta pesquisa foi desenvolvida com base na aplicação de protocolo para a avaliação de sistemas de medição de desempenho desenvolvido por Cândido, Lima e Barros Neto (2016), tratando-se, portanto, de um estudo de múltiplos casos (YIN, 2010).

Enquanto esses autores realizaram a análise com base em modelos descritos na literatura, por meio de critérios estruturados, observando a presença ou não destes, o presente estudo expande e aprofunda a análise para o campo qualitativo, focando-se em como o processo está sendo realizado, a partir de estudos de caso. O Quadro 1 ilustra a expansão realizada a partir do protocolo inicial.

Quadro 1 - Conjunção do protocolo de Cândido, Lima e Barros Neto (2016) e das perguntas norteadoras do presente estudo (fragmento ilustrativo para a etapa "Coletar e Processar Dados")

\begin{tabular}{|c|c|}
\hline $\begin{array}{c}\text { Protocolo de avaliação de Cândido, } \\
\text { Lima e Barros Neto (2016) } \\
\end{array}$ & $\begin{array}{l}\text { Questionamentos norteadores para a caracterização } \\
\text { minuciosa do sistema }\end{array}$ \\
\hline $\begin{array}{l}\text { O modelo apresenta um } \\
\text { procedimento ou dá diretrizes para a } \\
\text { criação dos dados necessários, a } \\
\text { forma com que estes são } \\
\text { transformados em informações e } \\
\text { como devem ser apresentados para } \\
\text { fornecer apoio à gestão? } \\
0 \text { - Não dá nenhuma diretriz. } \\
1 \text { - Dá diretrizes sobre a fonte dos } \\
\text { dados que serão utilizados e qual a } \\
\text { ferramenta que será utilizada para o } \\
\text { procedimento. } \\
2 \text { - Dá diretrizes de como deve ser a } \\
\text { infraestrutura necessária para gerar os } \\
\text { resultados e fornecer apoio à gestão. }\end{array}$ & $\begin{array}{l}\text { - Existem procedimentos definidos para a coleta e o } \\
\text { processamento dos indicadores de desempenho? Caso haja, } \\
\text { solicitar as planilhas/manuais de uso dos indicadores } \\
\text { - As informações contidas aos manuais de definição e uso de } \\
\text { indicadores de desempenho são suficientes para sua } \\
\text { operacionalização? } \\
\text { - Como os dados são processados e armazenados? } \\
\text { - Como as pessoas responsáveis pela coleta, processamento e } \\
\text { armazenamento dos dados foram instruídas? Existe alguma } \\
\text { estratégia para incentivar as pessoas a coletar os dados? Às vezes } \\
\text { existe a necessidade de cobrar para que as pessoas coletem os } \\
\text { dados? } \\
\text { - Existe algum procedimento para verificar se as pessoas estão } \\
\text { coletando corretamente os dados? Como? } \\
\text { - Qual a principal dificuldade que a empresa tem para realizar a } \\
\text { coleta e o processamento dos dados referentes aos indicadores de } \\
\text { desempenho? Em sua opinião, o que poderia ser feito para que } \\
\text { essas dificuldades fossem eliminadas? }\end{array}$ \\
\hline
\end{tabular}


O protocolo de avaliação foi submetido a um pré-teste, tendo em vista seu aprimoramento e validação, conforme sugerido por Marconi e Lakatos (2003). Assim, aplicou-se o roteiro com o diretor técnico e sócio proprietário de uma construtora e incorporadora na cidade de Fortaleza, que possui titulação acadêmica de doutor em engenharia industrial e forneceu importantes contribuições para o aprimoramento e a validação do instrumento de pesquisa. Entre as melhorias, ante a elevada duração da aplicação do pré-teste, o protocolo foi dividido em três subseções, dirigidas aos níveis estratégico, gerencial e operacional, conforme descrito no Quadro 2.

Assim, as entrevistas foram conduzidas com base em um roteiro que combinou questões abertas e fechadas. Cada gestor participante também foi indagado sobre sua percepção quanto à importância e ao grau de implantação das características, papéis e processos do sistema de medição de desempenho em sua empresa, atribuindo uma nota entre um e cinco, conforme a Tabela 1.

A percepção dos respondentes quanto à importância de uma característica, papel ou processo do SMD é um relevante direcionador de como se dá o processo de medição e gestão do desempenho nas organizações, o que justificou o emprego da escala de importância no presente estudo. Observa-se que, em casos em que o respondente acentua a importância de uma característica, papel ou processo, mas seu grau de utilização na empresa mostra-se baixo ou nulo, evidencia-se a existência de barreiras que impedem ou constringem sua adequada utilização. Por outro lado, quando a avaliação de importância é baixa, não se pode esperar um elevado grau de utilização, nem mesmo razoável, influenciando diretamente o processo de medição e gestão do desempenho.

O resultado foi calculado como a soma dos valores atribuídos individualmente pelos gestores, dividido pelo total possível, caso todos atribuíssem nota máxima, em forma percentual. Dessa forma, foi possível confrontar o grau estabelecido de desenvolvimento dos quesitos avaliados por Cândido, Lima e Barros Neto (2016) com base na literatura, com a realidade percebida pelos gestores do setor. Os autores puderam ainda descrever minuciosamente os quesitos que a empresa estava realmente atingindo, bem como atribuir uma nota para cotejar a realidade enquanto percebida pelos gestores e a percepção direta dos pesquisadores.

Assim, o primeiro resultado é evidenciado quantitativamente, confrontando a importância que os gestores conferem a cada característica, papel e processo do SMD da empresa, seu grau de implantação e a avaliação dos pesquisadores.

Importa salientar que não se analisou a efetividade das ações das empresas, ou seja, se essas ações têm efeito positivo para o desempenho, mas apenas sua constatação. Importa também estabelecer que não se analisaram circunstâncias específicas de ações deliberadas à parte de um bom ou mau desempenho. Investiga-se, na verdade, como o processo está estruturado para responder às diferentes circunstâncias. Assim, o estudo não se aprofunda nas estratégias gerenciais de desempenho, mas em sua estruturação para possibilitar sua efetivação.

Quadro 2 - Elementos do roteiro de entrevista

\begin{tabular}{|c|c|c|c|c|}
\hline Parte & $\begin{array}{c}\text { No de } \\
\text { Questões }\end{array}$ & $\begin{array}{c}\text { Nível de } \\
\text { aplicação }\end{array}$ & Descrição & $\begin{array}{c}\text { Fontes de } \\
\text { evidência }\end{array}$ \\
\hline $\begin{array}{c}\text { I - Caracterização da } \\
\text { empresa }\end{array}$ & 2 & $\begin{array}{c}\text { Estratégico } \\
\text { (diretoria) }\end{array}$ & $\begin{array}{c}\text { Informações sobre a empresa no que } \\
\text { diz respeito a posicionamento no } \\
\text { mercado, filosofia gerencial e porte, } \\
\text { entre outras características que } \\
\text { influenciam seu sistema de medição } \\
\text { de desempenho. }\end{array}$ & $\begin{array}{c}\text { Entrevista e } \\
\text { documentação }\end{array}$ \\
\hline $\begin{array}{c}\text { II - Características e } \\
\text { generalidades da } \\
\text { medição de } \\
\text { desempenho e seu uso } \\
\text { na empresa }\end{array}$ & 11 & $\begin{array}{c}\text { Estratégico } \\
\text { (diretoria) e } \\
\text { gerencial/ } \\
\text { operacional }\end{array}$ & $\begin{array}{c}\text { Tem por objetivo levantar qual a visão } \\
\text { da empresa em relação aos usos da } \\
\text { medição de desempenho, as } \\
\text { caraterísticas de seus sistemas, os } \\
\text { papéis que seu sistema cumpre e as } \\
\text { dificuldades para seu uso. }\end{array}$ & $\begin{array}{c}\text { Entrevista, } \\
\text { documentação } \\
\text { e observação }\end{array}$ \\
\hline $\begin{array}{c}\text { III - Caracterização do } \\
\text { processo de medição } \\
\text { de desempenho na } \\
\text { empresa }\end{array}$ & 21 & $\begin{array}{c}\text { Gerencial/ } \\
\text { operacional }\end{array}$ & $\begin{array}{c}\text { Tem por objetivo levantar, de maneira } \\
\text { geral, o que é feito e realizar uma } \\
\text { autocrítica sobre o sistema, por meio } \\
\text { de perguntas sobre os processos. }\end{array}$ & $\begin{array}{c}\text { Entrevista, } \\
\text { documentação } \\
\text { e observação }\end{array}$ \\
\hline
\end{tabular}


Tabela 1 - Grau de importância e de implantação das características, papéis e processos essenciais do SMD

\begin{tabular}{|c|c|c|c|c|c|c|c|c|c|c|}
\hline \multirow[b]{2}{*}{$\begin{array}{c}\text { Sem } \\
\text { importância }\end{array}$} & \multirow{2}{*}{\multicolumn{5}{|c|}{$\begin{array}{c}\text { Grau de importância } \\
\text { Extremamente } \\
\text { importante }\end{array}$}} & \multicolumn{5}{|c|}{ Grau de implantação } \\
\hline & & & & & & \multicolumn{2}{|c|}{\begin{tabular}{|c|} 
Não \\
implan- \\
tado \\
\end{tabular}} & \multicolumn{3}{|c|}{$\begin{array}{l}\text { Plenamente } \\
\text { implantado }\end{array}$} \\
\hline \multicolumn{6}{|l|}{ A. Características essenciais } & & & & & \\
\hline a.1. Possuir indicadores de desempenho & 1 & 2 & 3 & 4 & 5 & 1 & 2 & 3 & 4 & 5 \\
\hline $\begin{array}{l}\text { a.2. Ter uma infraestrutura de suporte } \\
\text { estabelecida }\end{array}$ & 1 & 2 & 3 & 4 & 5 & 1 & 2 & 3 & 4 & 5 \\
\hline Outro. Qual? & 1 & 2 & 3 & 4 & 5 & 1 & 2 & 3 & 4 & 5 \\
\hline \multicolumn{11}{|l|}{ B. Papéis essenciais } \\
\hline b.1. Medir o desempenho & 1 & 2 & 3 & 4 & 5 & 1 & 2 & 3 & 4 & 5 \\
\hline b.2. Gerir a estratégia & 1 & 2 & 3 & 4 & 5 & 1 & 2 & 3 & 4 & 5 \\
\hline b.3. Comunicar & 1 & 2 & 3 & 4 & 5 & 1 & 2 & 3 & 4 & 5 \\
\hline b.4. Influenciar o comportamento & 1 & 2 & 3 & 4 & 5 & 1 & 2 & 3 & 4 & 5 \\
\hline b.5. Proporcionar aprendizado e melhoria & 1 & 2 & 3 & 4 & 5 & 1 & 2 & 3 & 4 & 5 \\
\hline Outro. Qual? & 1 & 2 & 3 & 4 & 5 & 1 & 2 & 3 & 4 & 5 \\
\hline \multicolumn{11}{|l|}{ C. Processos essenciais } \\
\hline c.1. Definir e selecionar os indicadores & 1 & 2 & 3 & 4 & 5 & 1 & 2 & 3 & 4 & 5 \\
\hline c.2. Coletar e processar os dados & 1 & 2 & 3 & 4 & 5 & 1 & 2 & 3 & 4 & 5 \\
\hline c.3. Gerenciar a informação & 1 & 2 & 3 & 4 & 5 & 1 & 2 & 3 & 4 & 5 \\
\hline c.4. Avaliar e premiar & 1 & 2 & 3 & 4 & 5 & 1 & 2 & 3 & 4 & 5 \\
\hline c.5. Revisar sistematicamente & 1 & 2 & 3 & 4 & 5 & 1 & 2 & 3 & 4 & 5 \\
\hline Outro. Qual? & 1 & 2 & 3 & 4 & 5 & 1 & 2 & 3 & 4 & 5 \\
\hline
\end{tabular}

Com relação ao estudo de caso múltiplo realizado, os casos escolhidos são três empresas construtoras de Fortaleza, CE, cujas principais características são apresentadas no Quadro 3.

Essa escolha se deu pelo porte e representatividade das empresas no cenário local. O segundo critério foi o segmento de atuação - nos três casos, o mercado imobiliário. Sabe-se que, a depender do ramo de atuação e do nicho de mercado, as estratégias das empresas mudam, bem como seus objetivos organizacionais. Admitese ainda que os requisitos de qualidade dos clientes variam entre os diferentes tipos e categorias de construção, o que pode influenciar a concepção e a utilização dos sistemas de medição de desempenho das empresas. Por fim, as empresas também foram escolhidas pela facilidade de acesso dos autores da pesquisa, bem como pelo interesse e disponibilidade para participar do estudo.

Dessa forma, foram realizadas sete entrevistas com seis participantes de diferentes níveis hierárquicos das empresas, conforme o Quadro 4.

Além das entrevistas, buscou-se observar a forma de exposição dos resultados nas empresas, além de identificar e analisar documentos que comprovassem as práticas em investigação, conforme apresentado no Quadro 5.

O emprego de diferentes fontes de evidências bem como a triangulação entre elas pretenderam alcançar validade interna (YIN, 2010; TEIXEIRA; NASCIMENTO, 2011), o que pode mitigar limitações da estratégia de estudo de caso (BARBOSA, 2008) e a possiblidade de vieses inerentes ao caráter interpretativista da pesquisa de natureza qualitativa (CRESWELL, 2007).

As entrevistas foram transcritas e seus conteúdos tratados através de análise baseada nas categorias definidas a partir do modelo de Franco-Santos et al. (2007), levando à geração de categorias através de codificação, tabulação e interpretação de dados (KRIPPENDORFF, 2004; GIBBS, 2009; CHIZZOTI, 2011). Já os documentos obtidos com as empresas foram tratados como elementos secundários e comprobatórios das entrevistas, buscando-se atender a critérios de autenticidade e confiabilidade (CELLARD, 2010; RICHARDSON, 2011). 
Quadro 3 - Empresas participantes do estudo de caso

\begin{tabular}{|c|c|c|c|c|}
\hline $\begin{array}{c}\text { Nome } \\
\text { fictício }\end{array}$ & $\begin{array}{c}\text { Tempo de } \\
\text { atuação }\end{array}$ & Segmentação de mercado & Praça de atuação & Portfólio \\
\hline $\begin{array}{c}\text { Empresa } \\
\text { Alfa }\end{array}$ & 40 anos & $\begin{array}{c}\text { Edificações residenciais de médio e } \\
\text { alto padrão e obras industriais }\end{array}$ & Fortaleza (CE) & $\begin{array}{c}\text { Residencial: } 16 \\
\text { Industrial: } 8\end{array}$ \\
\hline $\begin{array}{c}\text { Empresa } \\
\text { Beta }\end{array}$ & 47 anos & $\begin{array}{c}\text { Edificações residenciais de médio e } \\
\text { alto padrão e obras comerciais }\end{array}$ & $\begin{array}{c}\text { Fortaleza (CE), } \\
\text { Teresina (PI) e } \\
\text { São Luís (MA) }\end{array}$ & Residencial: 38 \\
\hline $\begin{array}{c}\text { Empresa } \\
\text { Gama }\end{array}$ & 26 anos & $\begin{array}{c}\text { Edificações residenciais e } \\
\text { comerciais de médio e alto padrão }\end{array}$ & Fortaleza (CE) & $\begin{array}{c}\text { Residencial: } 17 \\
\text { Comercial: } 1\end{array}$ \\
\hline
\end{tabular}

Quadro 4 - Empresas participantes do estudo de caso

\begin{tabular}{|c|c|c|c|}
\hline Empresa & Nível estratégico & Nível tático/operacional & $\mathbf{N}^{\mathbf{0}}$ de participantes \\
\hline Empresa Alfa & Diretor técnico & Gerente de sala técnica & 2 \\
\hline Empresa Beta & Diretor técnico & $\begin{array}{c}\text { Coordenadora de sala técnica } \\
\text { Coordenadora da qualidade }\end{array}$ & 3 \\
\hline Empresa Gama & Diretor técnico & Diretor técnico & 1 \\
\hline
\end{tabular}

\section{Quadro 5 - Documentos fornecidos pelas empresas}

\begin{tabular}{|c|c|c|}
\hline Empresa & Documento & Informante \\
\hline \multirow{3}{*}{ Empresa Alfa } & $\begin{array}{l}\text { Trabalho de conclusão de curso de graduação com a } \\
\text { análise da aplicação do Balanced Scorecard na empresa }\end{array}$ & \multirow{2}{*}{$\begin{array}{l}\text { Gerente de } \\
\text { projetos }\end{array}$} \\
\hline & Ata de reunião de análise de indicadores de obra & \\
\hline & Livro com coletânea de artigos e história da empresa & Diretor técnico \\
\hline \multirow{4}{*}{ Empresa Beta } & Manual de indicadores de projeto & \multirow{3}{*}{$\begin{array}{l}\text { Coordenadora de } \\
\text { sala técnica }\end{array}$} \\
\hline & Manual de indicadores de planejamento & \\
\hline & Manual de indicadores de personalização & \\
\hline & Manual de indicadores da qualidade & $\begin{array}{l}\text { Coordenadora de } \\
\text { qualidade }\end{array}$ \\
\hline Empresa Gama & Manual de indicadores da empresa & Diretor técnico \\
\hline
\end{tabular}

\section{Resultados e discussões}

O resultado descritivo da avaliação é apresentado na Tabela 2. Para cada empresa avaliaram-se o grau de importância (1) e o grau de implantação (2) na percepção dos gestores participantes da pesquisa. Ademais, tomou-se a percepção dos autores do presente estudo quanto ao grau de implantação (3) a partir das evidências documentais, observacionais e das entrevistas obtidas durante a etapa de campo do estudo.

Com relação à importância, não se verifica diferenciação significativa na percepção dos gestores, tendo sido atribuída elevada importância a todos os quesitos, cujos valores foram superiores ao grau de implantação, na percepção dos gestores e dos pesquisadores deste estudo. Embora seja esperado que a avaliação dos gestores possa superestimar o desempenho de cada aspecto, por uma questão de viés, decorrente de se tratar de avaliação da própria empresa, isso sugere que os gestores reconhecem a importância das características, papéis e processos, mas existem barreiras para sua efetiva implantação na empresa, as quais são exploradas em profundidade a seguir.

\section{Análise das características dos SMD das empresas}

Em relação às características, observou-se o cumprimento dos requisitos de possuir indicadores de desempenho vinculados à estratégia para as três empresas estudadas, embora essa vinculação não esteja plenamente explícita, especialmente na percepção do diretor técnico da Empresa Gama, que atribuiu nota três para os subitens em questão. Esta é, portanto, uma oportunidade de aprimoramento para as três empresas: tornar mais evidente a vinculação entre os indicadores e as estratégias. Para tanto, existem modelos que 
permitem a rápida visualização dessas informações, a exemplo das matrizes propostas por Kagioglou, Cooper e Aquad (2001) e Kaplan e Norton (1992, 1996), entre outros.

Já a infraestrutura de suporte recebeu, em geral, grau de avaliação intermediário, tanto na perspectiva dos gestores das empresas, quanto na percepção dos autores do estudo. Essa dificuldade também é manifestada na literatura. Em Cândido, Lima e Barros Neto (2016) apenas 52\% dos modelos de SMD abaixados apresentavam discussões sobre a infraestrutura do sistema.

Nesse contexto, observou-se que os SMD das Empresas Alfa e Gama são executados com planilhas eletrônicas, constituindo-se em uma oportunidade de aprimoramento o uso de procedimentos informatizados de mais alto nível. Já para a Empresa Beta a infraestrutura de suporte ao SMD é um ponto crítico, tendo sido citada como o principal gargalo para a utilização desse sistema. Na empresa, há grande quantidade de planilhas eletrônicas, o que tornam ineficientes o processo de alimentação e a organização das informações de desempenho.

Verificou-se ainda que a Empresa Beta possui um sistema ERP (Enterprise Resource Planning). Porém, sua utilização é incipiente porque o sistema não é específico para o setor de construção civil, o que dificulta a adaptação de algumas funções à realidade da empresa, conforme a coordenadora de sala técnica:

Às vezes você tem o sistema, mas os processos da empresa não possuem o nível de maturidade suficiente para que você possa usá-lo. Assim, existem sistemas altamente robustos. Por exemplo, a gente usa o da TOTVS. O campo de atuação deles é muito grande, já que não é um sistema específico de construção civil, atuando em várias áreas... Às vezes, como não tem o processo muito bem definido, a ferramenta está lá disponível e a gente não sabe como utilizá-la. Mas hoje o maior gargalo na minha opinião é este: $T I$.

Isso torna o processo pouco produtivo e com risco de se basear em informações desatualizadas, constituindose em uma oportunidade de aprimoramento sua integração. Discussões mais aprofundadas sobre ERP e medição de desempenho são realizadas por Skibniewski e Ghosh (2009).

Tabela 2 - Avaliação descritiva das características, papéis e processos

\begin{tabular}{|c|c|c|c|c|c|c|c|c|c|c|c|c|c|c|c|}
\hline \multirow{3}{*}{ Itens } & \multicolumn{5}{|c|}{ Alfa } & \multicolumn{7}{|c|}{ Beta } & \multicolumn{3}{|c|}{ Gama } \\
\hline & \multicolumn{2}{|c|}{ Diretor } & \multicolumn{2}{|c|}{ Gestor A } & \multirow{2}{*}{$\frac{\text { Pesq. }}{(3)}$} & \multicolumn{2}{|c|}{ Diretor } & \multicolumn{2}{|c|}{ Gestor B } & \multicolumn{2}{|c|}{ Gestor C } & \multirow{2}{*}{$\frac{\text { Pesq. }}{\text { (3) }}$} & \multicolumn{2}{|c|}{ Diretor } & \multirow{2}{*}{$\frac{\text { Pesq. }}{\text { (3) }}$} \\
\hline & (1) & $(2)$ & (1) & (2) & & (1) & $(2)$ & (1) & (2) & (1) & (2) & & (1) & $(2)$ & \\
\hline \multicolumn{16}{|c|}{ A. Características essenciais } \\
\hline a.1 & 5 & 5 & 5 & 5 & 5 & 5 & 5 & 5 & 4 & 5 & 3 & 5 & 5 & 3 & 5 \\
\hline b.2 & 5 & 4 & 5 & 3 & 3 & 4 & 4 & 5 & 3 & 4 & 3 & 3 & 4 & 3 & 3 \\
\hline \multicolumn{16}{|c|}{ B. Papéis essenciais } \\
\hline b.1 & 5 & 5 & 5 & 5 & 3 & 5 & 4 & 5 & 4 & 5 & 5 & 3 & 5 & 3 & 3 \\
\hline b.2 & 5 & 5 & 5 & 3 & 5 & 4 & 5 & 5 & 3 & 5 & 3 & 5 & 4 & 3 & 5 \\
\hline b.3 & 5 & 4 & 5 & 4 & 3 & 4 & 5 & 5 & 3 & 4 & 3 & 3 & 5 & 3 & 5 \\
\hline b.4 & 5 & 4 & 5 & 4 & 5 & 5 & 3 & 4 & 3 & 4 & 2 & 3 & 4 & 3 & 0 \\
\hline b.5 & 5 & 5 & 5 & 4 & 3 & 5 & 3 & 5 & 4 & 5 & 2 & 3 & 5 & 3 & 3 \\
\hline \multicolumn{16}{|c|}{ C. Processos essenciais } \\
\hline c. 1 & 5 & 5 & 5 & 5 & 0 & 5 & 5 & 5 & 4 & 5 & 5 & 5 & 5 & 4 & 5 \\
\hline c. 2 & 5 & 5 & 5 & 4 & 0 & 5 & 4 & 5 & 3 & 5 & 5 & 5 & 5 & 4 & 3 \\
\hline $\begin{array}{l}\text { c. } 3 \\
\end{array}$ & 5 & 4 & 5 & 4 & 3 & 4 & 3 & 5 & 3 & 3 & 3 & 3 & 5 & 4 & 3 \\
\hline C. 4 & 5 & 4 & 4 & 5 & 3 & 5 & 4 & 5 & 3 & 4 & 5 & 3 & 3 & 2 & 0 \\
\hline c. 5 & 5 & 4 & 5 & 5 & 3 & 5 & 3 & 4 & 3 & 4 & 2 & 0 & 3 & 1 & 5 \\
\hline
\end{tabular}

Nota: Legenda:

(1) importância na visão dos gestores;

(2) implementação, visão gestores;

(3) implementação, visão pesquisadores.

a. 1. a c. 5. correspondem à descrição utilizada na Tabela 1. 


\section{Análise dos papéis dos SMD das empresas}

Em relação ao grau de importância conferido pelos gestores aos papéis exercidos por seus SMD, as avaliações para as Empresas Alfa e Beta foram majoritariamente elevadas, ressaltando a relevância desses papéis. Na Empresa Gama, por outro lado, o diretor atribuiu importância mediana para os papéis de influenciar o comportamento e proporcionar aprendizado e melhoria - nota 4.

Na Empresa Alfa verificou-se congruência entre o diretor e o gestor, que atribuíram grau de utilização 5 para medir o desempenho e 5 e 4 para proporcionar aprendizado e melhoria. Salienta-se, por fim, que todos os papéis receberam avaliação elevada para a utilização entre os respondentes da empresa, à exceção do papel gerir a estratégia, que recebeu nota 5 do diretor técnico e apenas 3 do gerente de sala técnica. Essa distinção entre os níveis estratégico e tático/operacional pode estar atrelada às atribuições e modos de utilização das informações que os cargos dos respondentes possuem.

Medir o desempenho, gerir a estratégia e comunicar são os papéis do SMD da Empresa Beta com maior grau de utilização, segundo seus gestores. Estes avaliam como apenas medianos os níveis de adoção dos papéis de comunicar e de influenciar o comportamento. Apesar de o papel de proporcionar aprendizado e melhoria ter sido considerado de suma importância, sua implantação foi avaliada como baixa. Além disso, enquanto o diretor atribuiu nota 3 para o papel em questão, a coordenadora de sala técnica e a coordenadora da qualidade conferiram notas 4 e 2 respectivamente, tendo sido o item com maior disparidade de toda a avaliação.

Neste ponto, a coordenadora da qualidade citou, inclusive, questionamentos realizados pela certificadora contratada para avaliar a implantação da ISO 9001.

[...] vocês têm muitos indicadores, muitos indicadores bons, mas eu não vejo a melhoria em cima desses indicadores. Vocês estão com um indicador abaixo da meta. Vocês estão fazendo alguma coisa? Qual a ação? O que vocês estão melhorando? Qual o plano de ação para isso mudar? Eu vejo que às vezes a gente mede, mede, mede, mede e chega naquele nível, na meta de $80 \%$ que a gente quer, mas os outros $20 \%$ a gente está fazendo alguma coisa para evoluir? Para até aumentar a nossa meta com o passar do tempo?

Por fim, não se verificou na Empresa Gama evidência de uso para o papel de influenciar o comportamento. Vale destacar que esta foi a única empresa que ressaltou o uso do sistema para comunicar os resultados interna e externamente. Seu diretor técnico afirmou que comunica os resultados a seus clientes/usuários finais, seja por meio da divulgação do avanço físico em seu site, seja apresentando para seus investidores as não conformidades da auditoria do sistema de gestão da qualidade.

Observou-se que o papel com menor grau de implantação percebido pelos respondentes foi o de influenciar o comportamento, resultado que corrobora estudo de Cândido, Lima e Barros Neto (2016), que verificaram que apenas 25\% dos modelos analisados apresentavam diretrizes para esse papel. Esse ponto é crítico, uma vez que estabelecer uma cultura de melhoria a partir do SMD é de fundamental importância (SINK; TUTTLE, 1993; KENNERLEY; NEELY, 2002).

Como um dos elementos básicos de um SMD são as pessoas (KUENG; ANDREAS; WETTSTEIN, 2001), sem esse papel os funcionários podem focar na produção de um bom indicador (meio), em detrimento de gerar valor para a empresa (fim) (SINK; TUTTLE, 1993). Ao negligenciar tal papel, "consequências indesejáveis e não intencionais são prováveis de ocorrer quando um sistema é projetado ou usado em circunstâncias diferentes daquelas originalmente assumidas” (FRANCO-SANTOS; OTLEY, 2018, p. 726, tradução nossa).

Cotejando as percepções dos gestores e dos pesquisadores quanto ao nível de adoção dos papéis, observa-se que aqueles possuem avaliações mais elevadas, diferença que se apresenta mais destacadamente na avaliação da Empresa Alfa. Embora esperado, por uma questão de viés, de modo geral, a indústria da construção civil é considerada atrasada e com processos de gestão e de construção fragmentados e de baixa maturidade (AFTAB et al., 2016), o que respalda o resultado encontrado.

Especificamente sobre a temática deste estudo, os gestores tendem a considerar apenas a mensuração dos indicadores, e não relacionam diretamente a seu modelo de gestão as informações obtidas destes, caracterizando a inexistência de um processo cíclico de medir e gerenciar o desempenho.

\section{Análise dos processos dos SMD das empresas}

Conforme a estrutura conceitual adotada, foram considerados processos típicos de uma medição de desempenho a seleção e definição de indicadores e a coleta e o processamento dos indicadores. Já os processos de gerenciar as informações, avaliar e premiar, e revisar foram considerados como de gestão de desempenho. 
Assim, esta subseção foi dividida na análise dos processos que sustentam a medição e nos processos para gestão de desempenho.

\section{Processos para medir o desempenho}

Em relação à importância conferida pelos gestores aos processos, novamente as avaliações para as Empresas Alfa e Beta foram majoritariamente elevadas, pois todas as notas foram 4 e 5 , à exceção a da coordenadora da qualidade, que conferiu nota 3 para gerenciar a informação. Na Empresa Gama, por outro lado, o diretor técnico atribuiu importância mediana para os processos de avaliar e premiar e de revisar sistematicamente (3 para ambos), embora sua avaliação de importância dos demais processos reflita a opinião geral dos gestores de Alfa e Beta.

No tocante à percepção dos gestores acerca do grau de implantação, como esperado, verificaram-se avaliações aderentes ao grau de importância por eles atribuído, de modo que processos considerados menos importantes foram também aqueles com menor nível de adoção. Nesse mesmo quesito, a percepção dos pesquisadores superou a percepção dos respondentes na avaliação dos processos de definir e selecionar os indicadores (nas Empresas Beta e Gama), de coletar e processar os dados (na Empresa Beta), e de revisar sistematicamente (na Empresa Gama).

Tais resultados parecem controversos, uma vez que se espera maior rigor por parte dos pesquisadores e uma avaliação mais elevada pelos gestores das empresas. Entretanto, uma análise mais aprofundada pode sugerir que os gestores possuem um grau de exigência alto para esses processos ou que a eficácia e a eficiência dos processos não estejam sendo satisfatórias, o que provoca uma avaliação diminuída.

Destaca-se ainda que não foram observadas evidências na Empresa Alfa com relação ao processo de coletar e processar os dados. O mesmo ocorreu na Empresa Beta para o processo de revisar sistematicamente, e na Empresa Gama com relação a avaliar e premiar.

\section{Seleção e definição dos indicadores}

Em relação à seleção e definição dos indicadores, as Empresas Beta e Gama possuem manuais de indicadores. Por exemplo, a Empresa Beta é dividida organizacionalmente em unidades gerenciais básicas (UGB), e seus indicadores estão relacionados a estas. Cada UGB possui uma missão, clientes internos, requisitos dos clientes, indicadores, metas, processo operacional e item de verificação, conforme a Figura 3.

Figura 3 - Manual de Gerenciamento de Rotina da UGB Controle da Qualidade (Parte 1/2)

\begin{tabular}{|c|c|c|c|c|c|c|}
\hline $\begin{array}{c}\text { Missão } \\
\text { da UGB }\end{array}$ & $\begin{array}{c}\text { CLINTES DA } \\
\text { UGB }\end{array}$ & $\begin{array}{c}\text { PRODUTOS } \\
\text { DA UGB } \\
\text { (Requisitos } \\
\text { dos Clientes) }\end{array}$ & INDICADOR & META & $\begin{array}{l}\text { PROCESSO } \\
\text { (Procedimento } \\
\text { Operacional) }\end{array}$ & $\begin{array}{c}\text { ITEM DE } \\
\text { VERIFICA- } \\
\text { ÇÃO }\end{array}$ \\
\hline \multirow{2}{*}{$\begin{array}{l}\text { Assegurar } \\
\text { o nível de } \\
\text { qualidade } \\
\text { do } \\
\text { produto } \\
\text { das obras }\end{array}$} & $\begin{array}{l}\text { Clientes MM } \\
\text { Obras }\end{array}$ & IDQ & $\begin{array}{l}\text { Atendimento à } \\
\text { demanda de } \\
\text { inspeção do } \\
\text { IDQ das obras }\end{array}$ & $\begin{array}{l}\text { 95\% de } \\
\text { inspeção da } \\
\text { amostra do } \\
\text { IDQ das } \\
\text { obras }\end{array}$ & \multirow[b]{2}{*}{$\begin{array}{l}\text { PG } 15 \text { - } \\
\text { Gestão de } \\
\text { Controle da } \\
\text { Qualidade }\end{array}$} & $\begin{array}{l}\text { Planilha de } \\
\text { Amostras - } \\
\text { IDQ }\end{array}$ \\
\hline & $\begin{array}{l}\text { Clientes MM } \\
\text { Obras UGB } \\
\text { Relacionamen } \\
\text { tos }\end{array}$ & $\begin{array}{l}\text { Vistorias e } \\
\text { retornos dos } \\
\text { apartamentos } \\
\text { no prazo }\end{array}$ & $\begin{array}{l}\text { Prazo de } \\
\text { atendimento à } \\
\text { demanda de } \\
\text { vistorias e } \\
\text { retornos de } \\
\text { apartamentos }\end{array}$ & $\begin{array}{l}90 \% \text { das } \\
\text { vistorias } \\
\text { realizadas até } \\
\text { dois dia após } \\
\text { a data } \\
\text { prevista pela } \\
\text { obra }\end{array}$ & & $\begin{array}{l}\text { Programação } \\
\text { de vistoria e } \\
\text { retorno dos } \\
\text { apartamentos }\end{array}$ \\
\hline
\end{tabular}

Fonte: Empresa Beta. 
Além das informações contidas na Figura 2, o manual da Empresa Beta apresenta:

(a) o tipo de treinamento necessário para executar o processo;

(b) a frequência de medição;

(c) o responsável;

(d) como deve ser medido;

(e) a base dos dados; e

(f) a ferramenta para gerir o indicador.

Destarte, os manuais de indicadores das Empresas Beta e Gama foram comparados com a estrutura de definição proposta por Neely et al. (1997). Verificaram-se no manual da Empresa Beta itens que podem ser incorporados à estrutura de Neely et al. (1997), quais sejam: (i) treinamento - tipos de conhecimentos teóricos, ferramentais e metodológicos que o responsável pela medição deve receber para executar a medição; e (ii) item de verificação - relação dos documentos comprobatórios para verificação da consistência e validade dos dados medidos.

Destaca-se ainda que o diretor técnico da Empresa Gama apontou o processo definir e selecionar indicadores como um desafio:

O grande desafio dessa temática de medição de desempenho é sim identificar aquilo que é importante para o seu setor, para o seu nicho. Identificou? Ok! Mas agora o quê é que vale a pena coletar, processar e acompanhar rotineiramente?

Tal dificuldade encontra amparo na literatura de gestão da construção, como se vê em Souza, Cândido e Barros Neto (2018), bem como na literatura das ciências administrativas (NEELY; BOURNE, 2000), o que permite posicionar a problemática como na fase de medição de desempenho integrada - na proposta de evolução de Bititci et al. (2012). Conforme os autores, nessa fase se deu extrema importância em o que se medir e como as medidas produziam alinhamento estratégico.

\section{Coleta e processamento dos dados}

No que se refere à coleta e ao processamento dos dados, verificaram-se dificuldades basicamente na Empresa Alfa, que não possui padronização para esse processo, constituindo-se um ponto de aprimoramento. A formalização de processos é uma importante característica de um sistema de medição (TONI; TONCHIA, 2001). O registro e o treinamento acerca dos indicadores podem minimizar desvios de interpretação destes, além de institucionalizar o conhecimento da empresa, uma vez que os indicadores servirão para outros julgarem o desempenho (FLAPPER; FORTUIN; STOOP, 2006).

Ainda nesse caso específico, o SMD da Empresa Alfa não dá diretrizes sobre a fonte dos dados que serão utilizados, tampouco a ferramenta para o procedimento, corroborando as dificuldades identificadas na literatura, de acordo com Cândido, Lima e Barros Neto (2016), o que conferiu avaliação zero por parte dos pesquisadores. Esse item pode ser aprimorado também com o uso do manual de indicadores proposto e com treinamento dos responsáveis pela coleta. Tem-se como premissa que a coleta de dados, quando mal estabelecida, pode tornar o SMD improdutivo e oneroso para a empresa.

A Empresa Beta possui procedimentos definidos para coleta e processamento de seus indicadores. Mais que isso, os gestores julgam que as informações contidas nos manuais dos indicadores são suficientes para sua operacionalização, o que confere a esse processo nota máxima na avaliação realizada. Já na Empresa Gama são usadas planilhas eletrônicas, tendo sido apontado pelo diretor técnico como crítico o incentivo da diretoria para que os indicadores sejam coletados rotineiramente. O diretor apontou ainda não ser necessário um processo para verificar se as pessoas estão coletando corretamente os dados: "Coletar e processar já é um procedimento de controle, então por que eu vou criar uma controladoria do controle?” (diretor técnico da Empresa Gama).

Ainda, o SMD da Empresa Gama não dá diretrizes sobre a fonte dos dados que serão utilizados e sobre qual ferramenta será utilizada para o procedimento, corroborando dificuldades identificadas na literatura de que não há um consenso de quais informações são necessárias para a utilização de indicadores de desempenho, demonstrado pela quantidade de estruturas encontradas na literatura, tais como as de Kagioglou, Cooper e Aquad (2001), Kaplan e Norton (1992, 1996), Medori e Steeple (2000) e Sink e Tuttle (1993). 


\section{Processos para gerir o desempenho}

\section{Gerenciar a informação}

Para o processo de gerenciar a informação, na Empresa Alfa, apesar de os gestores não contarem com um procedimento padronizado para a aquisição e o processamento dos dados, a interface para transferência da informação é bem formalizada, sob a forma de ata de reunião. Essa ata contém os indicadores da obra, os quais são apresentados em forma de gráfico, ilustrações e índices. Isso também garante que as informações cheguem aos interessados e estejam disponíveis para a tomada de decisão. Vale salientar que os parceiros (subcontratados) e os fornecedores também participam dessa reunião de análise dos indicadores. Esse é um ponto positivo, pois os responsáveis pelos processos estão inseridos na análise dos resultados e na proposição de melhorias. Além disso, são utilizados painéis em obra para divulgação dos resultados, conforme a Figura 4.

Na empresa não existem diretrizes para garantir a integridade e a consistência dos resultados da medição, bem como a forma com que estes devem ser usados, razão pela qual os pesquisadores atribuíram nota 3 para o processo em questão.

Para a Empresa Beta, o gerenciamento da informação foi o processo menos importante entre os avaliados e o segundo pior em relação ao grau de implantação, tendo recebido dos três respondentes nota 3 . Ainda na Empresa Beta foram verificadas boas práticas, como o uso de dispositivos para melhoria da comunicação (por exemplo, dispositivos visuais para disseminação das informações no canteiro de obras). Acresce-se a isso o fato de que as interfaces desses dispositivos são pensadas para cada público-alvo. Por exemplo, para os operários, em vez de serem utilizados gráficos, são utilizadas imagens com rostos sorrindo, neutros ou tristes, o que remete à sensação de bom ou mau desempenho.

A Empresa Gama dá diretrizes para garantir que a informação chegue aos interessados e esteja disponível para a tomada de decisão por meio da disseminação dos indicadores em um painel na sala de engenharia, reuniões semanais e relatórios enviados à diretoria. Assim como na Empresa Alfa, na Empresa Gama também há participação dos parceiros (subcontratados) nessas reuniões de discussão.

\section{Avaliação e premiação}

Em relação à avaliação e premiação, os gestores da Empresa Alfa atribuíram alto grau de implantação, embora não exista um processo formalizado nem para a avaliação, nem para a premiação. O que há de fato é uma premiação para cada fase da obra, feita de acordo com o desempenho financeiro da etapa concluída.

Para a Empresa Beta, o processo de avaliação e premiação é o terceiro processo mais importante, apesar de os gestores terem conferido moderado grau de implantação. Observou-se disparidade entre a percepção dos respondentes da empresa, uma vez que o diretor técnico conferiu nota 4, a coordenadora de sala técnica nota 3 , e a coordenadora da qualidade nota 5 .

\section{Figura 4 - Painel de PPC na obra}

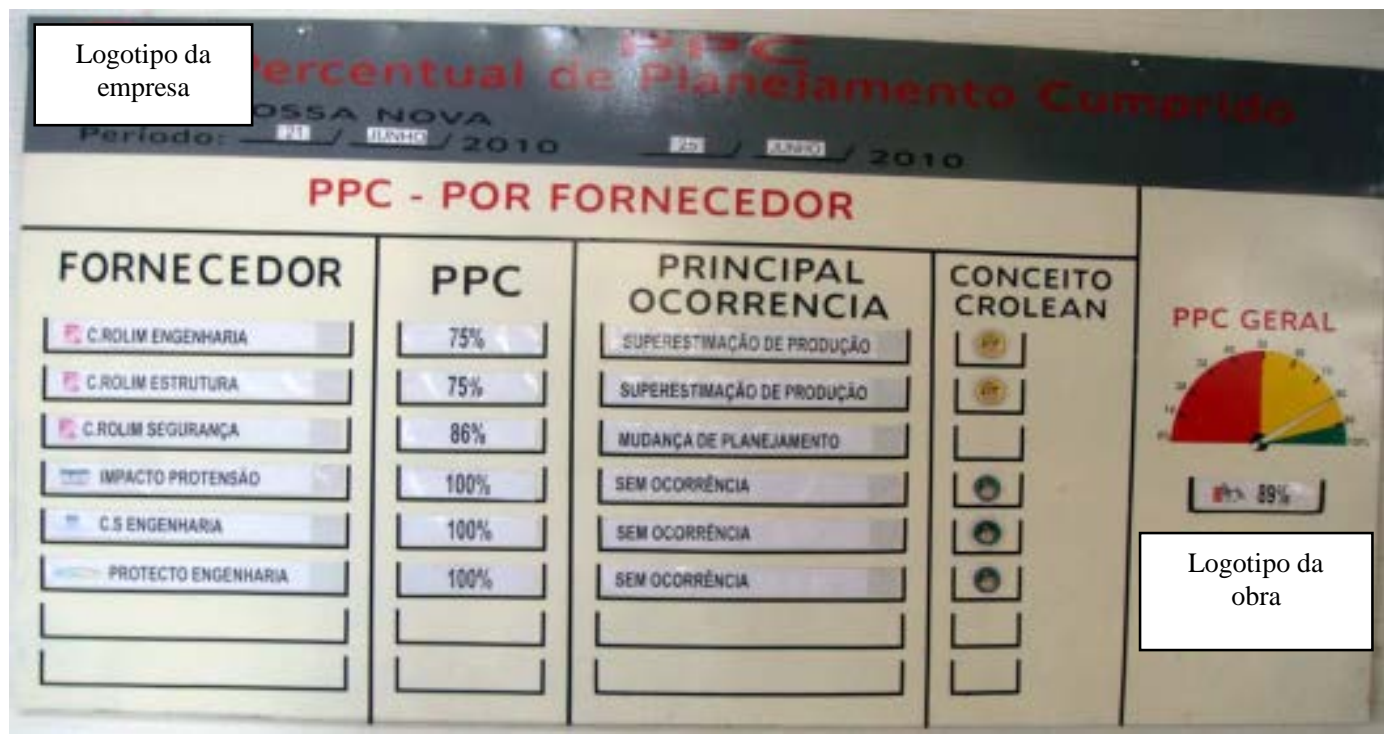


Em nível de organização, trimestralmente há uma reunião intitulada de “Reunião de Prestação Contas”. Nessa reunião cada área vai até seu diretor apresentar os resultados. Isso resulta no fechamento do indicador anual para cada área.

Em nível tático também são realizadas reuniões periódicas para discussão dos indicadores, conforme se pode observar no relato do diretor técnico da Empresa Beta: "Todo mundo fala em indicadores, todo mundo fica na expectativa de terminar o mês e apurar para ver o resultado do seu indicador. A gente já possui reuniões sistemáticas para discutir isso. Eu acho que é uma coisa muito natural”.

A prática de reuniões para discussão dos indicadores é um ponto positivo, pois a necessidade do uso dos indicadores deve perpassar apenas a comunicação dos resultados para níveis hierárquicos superiores. E mais: Sink e Tuttle (1993) e Kennerley e Neely (2002) apontam que criar uma cultura de medição é um passo importante para a efetiva implantação de qualquer SMD.

Quanto à premiação, existe uma política de remuneração variável para os gestores. Para a obra, a apuração é realizada bimestralmente, com a prática do benchmarking interno - entre diferentes obras da empresa. Porém, as premiações são de natureza simbólica, como um café da manhã especial, um almoço especial, a presença do diretor, a concessão de medalhas e troféus para os funcionários. Na avaliação realizada, a nota para esse processo foi 3, pois o processo não é formalizado e não se baseia em metas.

Já a Empresa Gama não pratica qualquer premiação. Durante a entrevista, seu diretor técnico afirmou não possuir sistema de recompensas: "Não há uma premiação, nenhuma bonificação". Isso reflete a baixa importância atribuída ao processo, que foi de apenas 3.

Portanto, uma oportunidade de melhoria para as Empresas Alfa e Beta é formalizar o processo de premiação vinculando recompensas a metas. Já para a Empresa Gama, ela deve criar a cultura de recompensas para estimular a melhoria, estando ela obviamente bem formalizada e baseada em metas. Isso é destacado por Safari (2016), para quem o pagamento de recompensas é crítico para aumentar a motivação ao apresentar um caso real de diferença de produtividade entre dois colaboradores de um mesmo nível hierárquico.

\section{Revisão sistemática}

Por fim, em relação à revisão do sistema, verifica-se que a Empresa Alfa não possui um processo estabelecido de revisar seus indicadores ou de revisar a consistência do sistema. Na verdade, há um processo não cíclico e não padronizado para a análise dos indicadores (se ainda refletem os objetivos da organização). Além disso, o gatilho que dispara esse processo não é claro.

O diretor técnico afirma que os indicadores já foram tão revisados ao longo da história da empresa que ele não vê a necessidade de mudança. Essa acomodação pode ser nociva, uma vez que não só os indicadores devem refletir as necessidades da empresa, mas sua operacionalização deve ser avaliada periodicamente. Por exemplo, ainda que um indicador seja estável e confiável, pode ser de difícil execução ou, ainda, pode se tornar uma atividade que gera sobrecarga devido às atribuições que o gestor já possui. Assim, um caminho para o aprimoramento do SMD da Empresa Alfa é estabelecer a revisão sistemática para os indicadores e para o sistema como um todo.

Na Empresa Beta a revisão sistemática do sistema é o quarto processo mais importante, porém obteve a pior avaliação quanto a seu grau de implantação, com nota 3 por parte do diretor técnico e da coordenadora de sala técnica, e 2 por parte da coordenadora da qualidade. Apenas os indicadores são revisados anualmente, segundo esta. Na verdade, segundo a coordenadora de sala técnica, a revisão empreendida pela empresa se dá para as metas dos indicadores, e não para os indicadores ou para o sistema como um todo. Assim, pode-se apontar que não existe um processo de revisão sistemática institucionalizado na empresa.

Por fim, a Empresa Gama pratica a revisão sistemática apenas por meio da análise das metas. Essa prática está aquém do esperado, uma vez que a utilidade, a eficiência e a consistência do sistema como um todo devem ser revisadas para que o sistema não se torne obsoleto e improdutivo. Além disso, esse processo é apontado pelo diretor técnico como o de menor grau de implantação, com nota 1 . O diretor técnico informou ainda que ao longo da história da empresa alguns indicadores foram eliminados e outros acrescentados. De fato, a revisão sistemática em sua empresa ocorre de forma intuitiva, não estruturada, focando-se na revisão das metas dos indicadores em si. 


\section{Considerações finais}

Esta pesquisa teve como objetivo avaliar os processos de medição e gestão de desempenho em empresas construtoras. Para tal, com base em Cândido, Lima e Barros Neto (2016), expandiram-se os conceitos de medir e gerir o desempenho a partir da literatura de ciências administrativas, o que consubstanciou o protocolo dos estudos de caso realizados.

Com relação à importância dos itens analisados, na percepção dos gestores, todos os itens foram extremamente importantes e com valores maiores que o grau de implantação e de avaliação dos pesquisadores deste estudo, o que denota a importância dos pontos avaliados, ao passo em que revela a existência de barreiras para sua efetiva implantação, que foram identificadas e exploradas no estudo.

Com relação ao grau de implantação, os SMD das empresas estudadas são compatíveis com os achados de Cândido, Lima e Barros Neto (2016). Isso reforça o proposto pelos autores, acerca da evolução lenta das práticas de medição de desempenho na indústria da construção. Reforça também que ainda não é possível observar efetivamente os avanços promovidos pelos clubes de benchmarking em práticas consolidadas na gestão de empresas de construção (KORDE; LI; RUSSELL, 2005; NUDURUPATI; ARSHAD; TURNER, 2007; DENG; SMYTH; ANVUUR, 2012), tornando evidente o estágio incipiente dos atuais processos de medição das empresas.

Em especial, observou-se baixo grau de implantação do papel de proporcionar aprendizado e melhoria. Tal constatação evidencia a incipiência do tema nas empresas, uma vez que a medição dos elementos formais da empresa deve se alinhar aos elementos não formais (culturais e comportamentais) a fim de promover o desempenho.

Quanto aos processos, verificou-se como ponto mais crítico a revisão sistemática dos SMD. Evidenciaram-se especificamente fragilidades nos processos de gerenciamento da informação - devido à inexistência de diretrizes para garantir a integridade e a consistência dos resultados da medição, bem como a forma com que estes devem ser usados, e de avaliação e premiação - já que nenhuma empresa possuía um processo formalizado para a avaliação ou para a premiação. Por fim, com relação à revisão sistemática, verificou-se que apenas indicadores e suas metas são revisados, ou seja, não há revisão da utilidade, da eficiência e da consistência do sistema como um todo.

Assim, uma vez constatado que os processos relacionados a medir o desempenho (selecionar e definir, coletar e processar os indicadores) estão mais bem estruturados que os processos de gestão do desempenho (gerenciar a informação, avaliar e premiar, e revistar o sistema), conclui-se que as empresas ainda não possuem SMD capazes de permitir a gestão integrada de desempenho. A falta de integração fica ainda mais evidente ao se observar que os SMD estão focados em medir o desempenho, sem utilizá-lo para influenciar o comportamento e proporcionar aprendizado e melhoria, ou seja, constata-se um enfoque em controle técnico. Essa constatação permite ainda explicar, em parte, a natureza reativa dos principais indicadores utilizados no setor da construção.

Por fim, destaca-se que este trabalho pode contribuir para a literatura de gestão da construção por ser um dos primeiros estudos que analisam a medição e a gestão de desempenho como conceitos separados e interrelacionados, trazendo novas formas de examinar o tema com base em diversos conceitos que ascendem principalmente das ciências administrativas e econômicas. Além disso, expandiram-se as evidências empíricas no campo ao:

(a) apresentar o grau de importância que os gestores atribuem a diferentes características, papéis e processos da medição e gestão de desempenho;

(b) comparar essa percepção de importância com o grau de implantação percebido pelos participantes da pesquisa; e

(c) conhecer a percepção dos pesquisadores explorando substantivamente seu conteúdo.

Ao evidenciar formas de estruturar a medição e a gestão de desempenho em empresas construtoras, observase também uma contribuição prática. Neste ponto, é digno registrar que o manual de indicadores da Empresa Beta mostrou-se bem estruturado, contemplando 9 de 14 itens apresentados por Neely et al. (1997), sendo um modelo viável para que outras empresas definam adequadamente seus indicadores. Também merece relevo que na Empresa Beta há evidências de uma cultura de medição que serve como base para a gestão de desempenho, embora de forma incipiente. Destaca-se, por fim, que o protocolo de avaliação desenvolvido é capaz de articular diferentes conceitos (medir e gerir o desempenho) e componentes (características, papéis e 
processos), o que ajuda a direcionar os esforços de melhoria e de construção da teoria no campo do conhecimento.

Apesar das contribuições da pesquisa, como limitação se destaca a própria natureza dos estudos de caso qualitativos, que não visam a generalizações do ponto de vista estatístico, mas a compreender um fenômeno em profundidade, gerando proposições teóricas a serem verificadas em outros contextos. Aponta-se ainda como limitação que a avaliação realizada analisa apenas como a prática está estabelecida, sem analisar a eficácia de seus resultados. Assim, seria oportuno em estudos futuros:

(a) analisar a eficácia e a eficiência das práticas de medição e do uso em si das informações produzidas pelos sistemas de medição de desempenho; e

(b) através de estudos com caráter mais intervencionista, avaliar se e como os feedbacks gerados por esse tipo de avaliação levam a mudanças nas empresas, seja de mentalidade ou de implantação de ferramentas.

\section{Referências}

AFTAB, J. et al. Influence of project management performance indicators on project success in construction industry of Punjab, Pakistan. International Research Journal of Management Sciences, v. 4, n. 9, p. 511520, 2016.

AHMAD, S. B. S. et al. A Review of performance measurement for successful concurrent construction. Procedia - Social and Behavioral Sciences, v. 226, n. 1877, p. 447-454, 2016.

BARBOSA, L. O estudo de caso e a evolução da pesquisa em administração: limitações do método ou dos pesquisadores? In: ENCONTRO NACIONAL DOS PROGRAMAS DE PÓS-GRADUAÇÃO E PESQUISA EM ADMINISTRAÇÃO, 32., Rio de Janeiro, 2008. Anais [...] Rio de Janeiro: Anpad, 2008.

BITITCI, U. et al. Performance measurement: challenges for tomorrow. International Journal of Management Reviews, v. 14, n. 3, p. 305-327, 2012.

BITITCI, U. S. et al. Editorial: towards a theoretical foundation for performance measurement and management. International Journal of Management Reviews, v. 20, n. 3, p. 653-660, 2018.

BITITCI, U. S.; CARRIE, A. S.; MCDEVITT, L. Integrated performance measurement systems: a development guide. International Journal of Operations \& Production Management, v. 17, n. 5, p. 522534, 1997.

BOURNE, M. et al. Performance measurement and management: a system of systems perspective. International Journal of Production Research, v. 56, n. 8, p. 2788-2799, 2018.

BROWN, M. Keeping score: using the right metrics to drive world class performance. New York: Quality Resources, 1996.

CÂNDIDO, L. F.; LIMA, S. H. O.; BARROS NETO, J. P. Análise de sistemas de medição de desempenho na indústria da construção. Ambiente Construído, Porto Alegre, v. 16, n. 2, p. 189-208, abr./jun. 2016.

CELLARD, A. A análise Documental. In: POUPART, J. et al. (Org.). A pesquisa qualitativa: enfoques epistemológicos e metodológicos. Petrópolis: Vozes, 2010.

CHENG, L-Y.; WEN, D-C.; JIANG, H-C. The performance excellence model in construction enterprises: an application study with modelling and analysis. Construction Management and Economics, v. 32, n. 11, p. 1078-1092, 2014.

CHIZZOTI, A. Pesquisa qualitativa em Ciências Humanas e Sociais. 6. ed. Petrópolis: Vozes, 2011.

CHOONG, K. K. Has This large number of performance measurement publications contributed to its better understanding? A systematic review for research and applications. International Journal of Production Research, v. 52, n. 14, p. 4174-4197, 2013a.

CHOONG, K. K. Understanding the features of performance measurement system: a literature review. Measuring Business Excellence, v. 17, n. 4, p. 102-121, $2013 \mathrm{~b}$.

COSTA, D. B. et al. Benchmarking initiatives in the construction industry: lessons learned and improvement opportunities. Journal of Management in Engineering, v. 22, n. 4, p. 158-167, 2006.

CRESWELL, J. W. Projeto de pesquisa: métodos qualitativo, quantitativo e misto. 2. ed. Porto Alegre: Artmed, 2007. 
DENG, F.; SMYTH, H.; ANVUUR, A. A Critical review of PMS in construction: towards a research agenda. In: ANNUAL ARCOM CONFERENCE, 28., Edinburgh, 2012. Proceedings [...] Edinburgh: Arcom, 2012.

EVANS, J. R. An exploratory study of performance measurement systems and relationships with performance results. Journal of Operations Management, v. 22, n. 3, p. 219-232, 2004.

FITZGERALD, L. et al. Performance measurement in service business. London: CIMA, 1991.

FLAPPER, S. D. F.; FORTUIN, L.; STOOP, P. P. M. Towards consistent performance management system. International Journal of Operations \& Production Management, v. 16, n. 7, p. 27-37, 2006.

FOLAN, P.; BROWNE, J. A Review of performance measurement: towards performance management. Computers in Industry, v. 56, n. 7, p. 663-680, Sep. 2005.

FRANCO-SANTOS, M. et al. Towards a definition of a business performance measurement system. International Journal of Operations \& Production Management, v. 27, n. 8, p. 784-801, 2007.

FRANCO-SANTOS, M.; LUCIANETTI, L.; BOURNE, M. Contemporary performance measurement systems: a review of their consequences and a framework for research. Management Accounting Research, v. 23, n. 2, p. 79-119, 2012.

FRANCO-SANTOS, M.; OTLEY, D. Reviewing and theorizing the unintended consequences of performance management systems. International Journal of Management Reviews, v. 20, n. 3, p. 696 730, 2018.

GHALAYINI, A. M.; NOBLE, J. S. The changing basis of performance measurement. International Journal of Operations \& Production Management, v. 16, n. 8, p. 63-80, 1996.

GIBBS, G. Análise de dados qualitativos. Porto Alegre: Artmed, 2009.

HU, X.; LIU, C. profitability performance assessment in the Australian construction industry: a global relational two-stage DEA method. Construction Management and Economics, v. 34, n. 3, p. 147-159, 2016.

HULL, A. Managing business performance: the contrasting cases of two multiple retailers 1920 to 1939. Business History, v. 6791, p. 1-24, 2018.

KAGIOGLOU, M.; COOPER, R.; AQUAD, G. Performance management in construction: a conceptual framework. Construction Management and Economics, v. 19, p. 85-95, 2001.

KAPLAN, R. S.; NORTON, D. P. The balanced scorecard: measures that drive performance. Harvard Business Review, v. 70, n. 1, p. 70-79, 1992.

KAPLAN, R. S.; NORTON, D. P. Using the balanced scorecard as a strategic management system. Harvard Business Review, v. 74, n. 1, p. 75-85, 1996.

KENNERLEY, M.; NEELY, A. A Framework of the factors affecting the evolution of performance measurement systems. International Journal of Operations \& Production Management, v. 22, n. 11, p. 1222-1245, 2002.

KORDE, T.; LI, M.; RUSSELL, A. D. State-of-the-art review of Construction performance models and factors. In: CONSTRUCTION RESEARCH CONGRESS, 2005, San Diego, 2005. Proceedings... San Diego: ASCE, 2005.

KRIPPENDORFF, K. Content analysis: an introduction to its methodology. 2. ed. London: Sage, 2004.

KUENG, P.; ANDREAS, M.; WTTSTEIN, T. Performance measurement systems must be engineered. Communications of the Association for Information Systems, v. 7, n. 3, p. 1-27, 2001.

LAMPREIA, J.; MAJOR, M. J. A Behavioral perspective on the effects of using performance measurement systems in the companies: evidence from a case study. Dos Algarves: A Multidisciplinary e-Journal, v. 29, p. 83-101, 2017.

MARCONI, M. A.; LAKATOS, M. Fundamentos de metodologia científica. 5. ed. São Paulo: Atlas, 2003.

MAYA, R. A. Performance management for syrian construction projects. International Journal of Construction Engineering and Managament, v. 5, n. 3, p. 65-78, 2016. 
MEDORI, D.; STEEPLE, D. A Framework for auditing and enhancing performance measurement systems. International Jounal of Operations \& Production Management, v. 20, n. 5, p. 520-533, 2000.

MELLO, L. C. B. D. B.; AMORIM, S. R. L. O subsetor de edificações da construção civil no Brasil: uma análise comparativa em relação à União Europeia e aos Estados Unidos. Produção, v. 19, n. 2, p. 388-399, 2009.

MELNYK, S. A. et al. Is performance measurement and management fit for the future? Management Accounting Research, v. 25, n. 2, p. 173-186, 2014.

MICHELI, P.; MARI, L. The theory and practice of performance measurement. Management Accounting Research, v. 25, n. 2, p. 147-156, Jun. 2013.

NEELY, A. et al. Designing performance measures: a structured approach. International Journal of Operations \& Production Management, v. 17, n. 11, p. 1131-1152, 1997.

NEELY, A. et al. Performance measurement system design: developing and testing a process-based approach. International Journal of Operations \& Production Management, v. 20, n. 10, p. 1119-1145, 2000.

NEELY, A. The performance measurement revolution: why now and what next? International Journal of Operations \& Production Management, v. 19, n. 2, p. 205-228, 1999.

NEELY, A.; ADAMS, C.; CROWE, P. The performance prism in practice. Measuring Business Excellence, v. 5, n. 2, p. 6-12, 2001.

NEELY, A.; BOURNE, M. Why Measurement initiatives fail. Measuring Business Excellence, v. 4, n. 4, p. 3-7, 2000.

NEELY, A.; GREGORY, M.; PLATTS, K. Performance measuremente system design: a literature review and research agenda. International Journal of Operations \& Production Management, v. 15, n. 4, p. 80-116, 1995.

NEELY, A.; GREGORY, M.; PLATTS, K. Performance measuremente system design: a literature review and research agenda. International Journal of Operations \& Production Management, v. 15, n. 4, p. 80116, 1995.

NEYESTANI, B.; JUANZON, J. B. P. Developing an appropriate performance measurement framework for Total Quality Management (TQM) in Construction and Other Industries. IRA-International Journal of Technology \& Engineering, v. 5, n. 2, p. 32, 2016.

NUDURUPATI, S.; ARSHAD, T.; TURNER, T. Performance measurement in the construction industry: an action case investigating manufacturing methodologies. Computers in Industry, v. 58, n. 7, p. 667-676, Sep. 2007.

O’CONNEL, V.; O’SULLIVAN, D. The influence of lead indicator strength on the use of nonfinancial measures in performance management: evidence from CEO compensation schemes. Academy of Management Journal, v. 35, n. 6, p. 826-844, 2014.

OKWIR, S. O. et al. Performance measurement and management systems: a perspective from complexity theory. International Journal of Management Reviews, v. 20, n. 3, p. 731-754, 2018.

OTLEY, D. Performance management: a framework for management control systems research. Management Accounting Research, v. 10, p. 363-382, 1999.

RICHARDSON, R. J. Pesquisa social: métodos e técnicas. 3. ed. São Paulo: Atlas, 2011.

SAFARI, A. A New Quantitative-based performance management framework for service operations. Knowledge and Process Management, v. 23, n. 4, p. 307-319, 2016.

SINK, D. S.; TUTTLE, T. C. Planejamento e medição para performance. Rio de Janeiro: Qualitymark, 1993.

SKIBNIEWSKI, M. J.; GHOSH, S. Determination of key performance indicators with enterprise resource planning systems in engineering construction firms. Journal of Construction Engineering and Management, v. 135, n. 10, p. 965-978, 2009. 
SMITH, M.; BITITCI, U. S. Interplay between performance measurement and management, employee engagement and performance. International Journal of Operations and Production Management, v. 37, n. 9, p. 1207-1228, 2017.

SOUSA, D. S. V.; CÂNDIDO, L. F.; BARROS NETO, J. D. P. Medição de desempenho na construção civil: um estudo exploratório com construtoras cearenses. Ambiente Construído, Porto Alegre, v. 18, n. 1, p. 9-29, jan./mar. 2018.

TATICCHI, P.; TONELLI, F.; CAGNAZZO, L. Performance measurement and management: a literature review and a research agenda. Measuring Business Excellence, v. 14, n. 1, p. 4-18, 2010.

TEIXEIRA, J. C.; NASCIMENTO, R. Triangulação entre métodos na administração: gerando conversações paradigmáticas ou meras validações convergentes? In: ENCONTRO NACIONAL DOS PROGRAMAS DE PÓS-GRADUAÇÃO E PESQUISA EM ADMINISTRAÇÃO, 35., Rio de Janeiro, 2011. Anais [...] Rio de Janeiro: Anpad, 2011.

THE EUROPEAN FOUNDATION FOR QUALITY MANAGEMENT. The EFQM excellence model. Disponível em: http://www.efqm.org/. Acesso em: 15 set. 2019.

TONI, A.; TONCHIA, S. Performance measurement systems: models, characteristics and measures. International Journal of Operations \& Production Management, v. 21, n. 1-2, p. 46-70, 2001.

TSOLAS, I. E. Modelling profitability and effectiveness of greek-listed construction firms: an integrated DEA and ratio analysis. Construction Management and Economics, v. 29, n. 8, p. 795-807, 2011.

VILLARREAL, K. L.; PELLICER, E.; RODRIGUEZ, S. G. Performance indicators for developer and homebuilder mexican companies: a Delphi study. Revista de la Construcción, v. 16, n. 1, p. 133-144, 2017.

WEGELIUS-LEHTONEN, T. Performance measurement in construction logistics. International Journal of Production Economics, v. 69, n. 1, p. 107-116, 2001.

YANG, H. et al. A critical review of performance measurement in construction. Journal of Facilities Management, v. 8, n. 4, p. 269-284, 2010.

YIN, R. K. Estudo de caso: planejamento e métodos. 4. ed. Porto Alegre: Bookman, 2010.

Luis Felipe Cândido

Universidade Federal do Ceará | Rodovia BR-226, Km 03, s/n, Campus de Crateús, São Vicente | Crateús - CE - Brasil | CEP 63700-000 | Tel.: (88) 3691-9700 | E-Mail: luisfcandido2015@gmail.com

\section{Sergio Henrique de Oliveira Lima}

Centro de Ciências Sociais Aplicadas | Universidade Federal do Cariri | Av. Tenente Raimundo Rocha, 1639, Cidade Universitária | J uazeiro do Norte - CE - Brasil | CEP 63048-080 | Tel: (88) 3221-9546 | E-Mail: shlima05@gmail.com

\section{J ose de Paula Barros Neto}

Departamento de Engenharia Estrutural e Construção Civil | Universidade Federal do Ceará | Campus do Pici, s/n, Bloco 71 | Fortaleza CE - Brasil | CEP 60455-760 | Tel: (85) 3366-9600 | E-mail: barrosneto@gercon.ufc.br

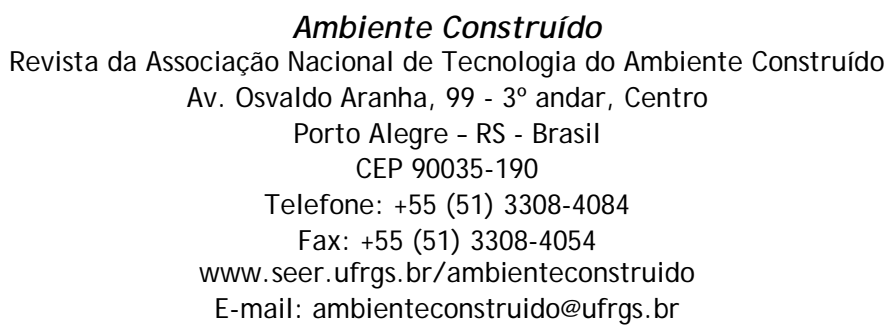

(c) (i) This is an open-access article distributed under the terms of the Creative Commons Attribution License. 